\title{
Racial and ethnic differences in motivation for educational achievement in the United States
}

Wei-Cheng Mau, Richard Lynn

\begin{abstract}
Data from the National Educational Longitudinal Study [National Educational Longitudinal Study, (1994). National Educational Longitudinal Study: second follow-up (Report No.94-374). Washington, DC: U.S. Department of Education] show that on standardised scores in mathematics, reading and science, the highest mean scores are obtained by Asians and whites and lower scores are obtained by Hispanics and blacks. The same differences are present for the number of hours per week devoted to homework. It is suggested that motivational differences expressed in the amount of homework undertaken contribute to the group differences in educational achievement. Statistically significant correlations between the amount of homework and educational achievement support this hypothesis. There are also group differences in intelligence parallel to those in educational achievement, suggesting both intelligence and motivation are involved in racial and ethnic differences in educational achievement.
\end{abstract}

Keywords: Race; Ethnic differences; Motivation; Educational achievement

\section{Introduction}

There is considerable research literature showing that in the United States there are racial and ethnic differences in the average educational achievement of school students. Typically, in mathematics the highest average scores are attained by Asians, followed in descending order by whites, Hispanics and blacks; while in language subjects, whites tend to perform better than Asians. This research literature has been reviewed by Flynn (1991) and Mau (1997). The same differences, so far as Asians and whites are concerned, have been found in the international studies of educational achievement in mathematics and science, in which the east Asian countries of Japan, Korea and Singapore have consistently outperformed the western nations of North America and Europe (Lynn, 1988; Keys, Harris \& Fernandes, 1996).

There is no consensus on the causes of these differences. In general terms, achievement can be regarded as a function of intelligence and motivation, and the racial and ethnic differences in educational achievement could be a function of differences in one or both of these. Some, such as Herrnstein and Murray (1994) and Jensen (1998), have proposed that differences in intelligence are involved, while others, including Flynn (1991) and Mau (1997), favour the motivational differences hypothesis. For the international differences in educational attainment, it has been proposed that higher intelligence and stronger motivation both contribute to the high educational standards attained in the East Asian countries (Lynn, 1988). However, international differences in educational achievement are affected by a number of extraneous factors like the number of school hours, the nature of the curriculum and so on, which are better controlled by within country studies such as the present, which provides new data on these issues from the United States.

\section{Method}

The data for this study are derived from the American National Educational Longitudinal Study (NELS) of 1988. This study consists of a nationally representative sample of 10th grade school students tested in 1990 on math, reading and science and retested in 1992. The students were also asked to give an estimate of the hours of homework they did per week out of school. We use these estimates of the 
number of hours of out of school homework per week as a measure of motivation on the grounds that this provides an index of the amount of motivational effort the students apply to their school performance.

The sampling procedure for the NELS was carried out by selecting a stratified sample of 1052 schools and selecting random samples of 25 students from each school. The school sample was stratified by size, urban versus rural, regional and percent minority population. The detailed sampling procedure is described by the National Center for Educational Statistics (1994). The numbers in the sample consist of 1406 Asians, 14,024 whites, 2922 Hispanics and 2260 African Americans.

Table 1

Mean scores for mathematics, reading and science and for hours of homework for Asian, white, Hispanic and black students

\begin{tabular}{|c|c|c|c|c|c|c|c|c|c|c|}
\hline \multirow[t]{2}{*}{ Variable } & \multirow[t]{2}{*}{ Grade } & \multicolumn{2}{|l|}{ Asian } & \multicolumn{2}{|l|}{ White } & \multicolumn{2}{|c|}{ Hispanic } & \multicolumn{2}{|l|}{ Black } & \multirow[t]{2}{*}{$F$} \\
\hline & & mean & S.D. & mean & S.D. & mean & S.D. & mean & S.D. & \\
\hline Math & 10 & 54.06 & 10.25 & 51.84 & 9.81 & 45.70 & 8.77 & 44.06 & 8.36 & 451.60 \\
\hline Reading & 10 & 51.20 & 0.12 & 51.78 & 9.76 & 46.23 & 8.76 & 44.96 & 9.11 & 335.13 \\
\hline Science & 10 & 51.85 & 10.49 & 52.11 & 9.77 & 45.32 & 8.18 & 43.39 & 7.69 & 544.67 \\
\hline Math & 12 & 53.82 & 9.93 & 51.88 & 9.71 & 45.82 & 8.94 & 44.18 & 8.53 & 363.89 \\
\hline Reading & 12 & 51.57 & 10.51 & 51.85 & 9.56 & 46.33 & 9.14 & 45.33 & 9.29 & 259.24 \\
\hline Science & 12 & 51.61 & 9.84 & 52.20 & 9.51 & 45.49 & 8.95 & 43.00 & 8.29 & 483.94 \\
\hline Homework & 10 & 3.21 & 1.94 & 2.46 & 1.71 & 2.34 & 1.57 & 2.20 & 1.49 & 51.71 \\
\hline Homework & 12 & 3.87 & 2.12 & 3.35 & 1.96 & 3.40 & 2.03 & 3.15 & 1.95 & 17.09 \\
\hline IQ & & 107.17 & 14.05 & 102.65 & 14.25 & 93.86 & 13.37 & 89.19 & 14.06 & \\
\hline
\end{tabular}

\section{Results}

The descriptive statistics for performance in the educational tests and the weekly hours of homework of the four racial and ethnic groups are shown in Table 1. Rows 1 to 6 give the mean test scores for mathematics, reading and science of the 10th and 12th graders. These scores were constructed on the basis of a mean of 50 and standard deviation of 10 for the total samples of 10th graders and of 12th graders. Notice that the mean scores in mathematics show the descending order Asians-whites-Hispanicsblacks, while for reading and science the same pattern is present except that there is no significant difference between the means of Asians and whites. Rows 7 and 8 give the mean number of hours of homework per week done by the four groups. Notice that the most hours are done by Asians, about the same number of hours are done by whites and Hispanics, whereas relatively fewer hours are done by blacks. Row 9 shows the mean IQ differences of the four groups obtained in 1986 in the standardisation sample of $6 \pm 17$ year olds of the British Ability Scales reported in Lynn (1996).

The statistical significance of the group differences in the educational tests and homework was tested by oneway analyses of variance. The results are shown in the right hand columns of Table 1 . All the F-values are significant at $p<0.001$, showing the presence of significant differences between the groups on all measures. Scheffe follow-up tests were calculated between all pairs which showed that all pair differences are statistically significant except between whites and Asians on reading and science and between whites and Hispanics on homework at both 10th and 12th grade.

It seems probable that the hours devoted to homework will make a contribution to educational attainment. Thus, the results showing that the racial and ethnic differences in the hours spent on homework tend to be associated with the differences in educational achievement suggest there is a motivational factor, indexed by hours of homework, contributing to the racial and ethnic differences in 
educational achievement. To verify this, correlations were computed between hours of homework and educational achievement for each group. These correlations are shown in Table 2 . They are all positive and statistically significant at the $0.01 \%$ level, confirming the hypotheses that the amount of time spent on homework contributes to educational attainment and that racial and ethnic differences in the amount of time spent on homework contribute to group differences in educational attainment.

Table 2

Product-moment correlations between homework at 10th and 12th grade and scores on math, reading and science

\begin{tabular}{|c|c|c|c|c|c|c|c|c|}
\hline & \multicolumn{2}{|l|}{ Asian } & \multicolumn{2}{|l|}{ White } & \multicolumn{2}{|c|}{ Hispanic } & \multicolumn{2}{|l|}{ Black } \\
\hline & 10th & 12 th & 10th & 12 th & 10th & 12 th & 10 th & 12 th \\
\hline Math & 0.387 & 0.332 & 0.305 & 0.245 & 0.348 & 0.175 & 0.272 & 0.278 \\
\hline Reading & 0.352 & 0.254 & 0.285 & 0.233 & 0.314 & 0.109 & 0.225 & 0.129 \\
\hline Science & 0.310 & 0.252 & 0.235 & 0.183 & 0.297 & 0.104 & 0.161 & 0.168 \\
\hline
\end{tabular}

\section{Discussion}

The results contain four points of interest. First, the general pattern of the group differences in mathematics, reading and science, in which the highest mean scores are obtained by Asians and whites, intermediate scores are obtained by Hispanics and the lowest mean scores by blacks confirm a number of previous studies reviewed by Flynn (1991) and Mau (1997). Second, the higher scores obtained by Asians as compared with whites on mathematics, but their lower scores on reading, are also consistent with previous results. This pattern of differences seems to reflect the profiles of cognitive abilities of the two groups, Asians being stronger than whites on non-verbal reasoning ability and whites being stronger than Asians on verbal ability. The evidence for this conclusion has been reviewed by Vernon (1982) and Flynn (1991). It may be a little surprising that Asians do not score higher than whites on science, especially in view of the international studies of educational attainment in science in which Asian 8th graders in Japan, South Korea and Singapore perform substantially better than those in the United States (Keys et al., 1996). It should be borne in mind, in considering these results, that American Asians include all those originally from the continent of Asia and its offshore islands such as the Philippines, whereas the countries with high levels of achievement in the international studies are confined to east Asia.

Third, the gradient of the educational attainment of the four racial and ethnic groups tends to be consistent with the amount of time they spend on homework. This suggests that time spent on homework may be a determinant of the group differences in educational achievement. Evidence for an association between time spent on homework and school grades has been presented by Cooper (1989) and Cooper, Lindsay, Nye and Greathouse (1998). This is corroborated in the present study by the significant positive correlations between educational attainment and time spent on homework among individuals. However, the magnitude of the correlations between homework and test scores is quite low, ranging between 0.387 and 0.104 . This is consistent with the results of Cooper. These correlations are lower than those typically obtained between intelligence and educational attainment, suggesting that intelligence is a more powerful determinant of educational attainment than motivation. There is also an exception to the generally positive associations in the group differences between homework and attainment in so far as Asians spend more time on homework than whites, but they do not perform better in reading and science. In fact, they perform slightly but not significantly less well. It should be observed that the direction of the causal association between amount of time spent on homework and educational attainment is not straightforward. While it seems reasonable to suppose that time spent on homework will make a positive contribution to educational attainment, it is also possible that educational attainment may affect hours 
spent on homework. A student who does poorly at school may become discouraged and decide to skimp on homework, while the student who does well at school is likely to be encouraged and spend time on homework. There may well be a positive feedback relationship between time spent on homework and educational attainment.

Fourth, the group differences in intelligence are associated with the differences in educational attainment in mathematics. They are also associated with the differences in reading and science, except for the anomaly that Asians obtain higher means on intelligence than whites but do not obtain higher means on reading and science. This pattern of results can be reasonably explained by the lower verbal ability of Asians, as compared with whites, which has been found in a number of studies reviewed by Vernon (1982) and Flynn (1991) and which could be expected to pull down their attainment in reading and science.

A plausible interpretation of the results is that the racial and ethnic differences in educational attainment are a joint function of differences in intelligence and motivation. The motivational component is indexed by the number of hours school students voluntarily devote each week to homework. This should probably be regarded as an expression of the personality trait of conscientiousness, posited as one of the 'big five' personality traits in contemporary personality theory. The trait of conscientiousness is described by Costa and McCrae (1992) in terms of conscientious versus negligent, hardworking versus lazy, well-organised versus disorganised, ambitious versus aimless and persevering versus quitting. MacDonald (1995), p. 534) describes the trait as consisting of "the ability to defer gratification, persevere in unpleasant tasks, pay close attention to detail and behave in a responsible, dependable manner". These look like descriptions of the typical Asian personality although whether there are racial and ethnic differences in conscientiousness underlying the differences in the amount of time devoted to homework, reported in this study, remains to be determined.

\section{References}

Cooper, H. (1989). Homework. White Plains, NY: Loongman.

Cooper, H., Lindsay, J. J., Nye, B., \& Greathouse, S. (1998). Relationships among attitudes about homework, amount of homework assigned and completed, and student performance. Journal of Educational Psychology, 90, 70-83.

Costa, P. T., \& McCrae, R. R. (1992). The five factor model and its relevance to personality disorder. Journal of Personality Disorders, 6, 343-359.

Flynn, J. R. (1991). Asian Americans. Hillsdale, NJ: Lawrence Erlbaum.

Herrnstein, R. J., \& Murray, C. (1994). The Bell Curve. New York: Free Press.

Jensen, A. R. (1998). The $g$ factor. Westport, CT: Praeger.

Keys, W., Harris, S., \& Fernandes, C. (1996). Third International Mathematics and Science Study. Slough, Berks: NFER.

Lynn, R. (1988). Educational achievement in Japan. London: MacMillan.

Lynn, R. (1996). Racial and ethnic differences in the United States on the British Ability Scales. Personality and Individual Differences, 20, 271-273.

MacDonald, K. (1995). Evolution, the five factor model and levels of personality. Journal of Personality, 63, 525-567.

Mau, W.-C. (1997). Parental influences on the high school students' academic achievement: a comparison of Asian immigrants, Asian Americans and white Americans. Psychology in the Schools, 34, 267277.

National Center for Educational Statistics (1994). National Educational Longitudinal Study: second followup (Report No.94-374). Washington, DC: U.S. Department of Education.

Vernon, P. E. (1982). The abilities and achievements of orientals in North America. New York: Academic Press. 